\title{
LA REFORMA DE LOS DECRETOS- LEYES EN ITALIA Y SUS POSIBLES LECCIONES EN ESPAÑA
}

FERNANDO SANTAOLALLA LÓPEZ 
SUMARIO

I. INTRODUCCIÓN: LA REFORMA CONSTITUCIONAL ITALIANA. II. LA CUESTIÓN DE LOS DECRETOS LEYES: SIMILITUDES Y DIFERENCIAS. III. LA APLICACIÓN PATOLÓGICA DE LOS DECRETOS LEYES. IV. LAS DISTINTAS SITUACIONES DE HECHO ENTRE ITALIA Y ESPAÑA. V. LA RESPUESTA DE LA CORTE CONSTITUCIONAL. VI. LA REFORMA DEL ARTÍCULO 77. VII. LECCIONES QUE PUEDEN EXTRAERSE PARA EL CASO ESPAÑOL: 1. Forma de la convalidación de los decretos-leyes. 2. Sobre el control de los hechos determinantes de los decretosleyes. 3. Sobre los límites materiales y formales de los decretos-leyes. VIII. CONCLUSIÓN. 


\title{
LA REFORMA DE LOS DECRETOS- LEYES EN ITALIA Y SUS POSIBLES LECCIONES EN ESPAÑA
}

\author{
FERNANDO SANTAOLALLA LÓPEZ* \\ Letrado de las Cortes Generales \\ Prof. Titular de Derecho constitucional (excd.)
}

\section{INTRODUCCIÓN: LA REFORMA CONSTITUCIONAL ITALIANA**}

El diario oficial (Gazzetta Ufficiale) de la República italiana publicó el 16 de abril de 2016 la ley de reforma constitucional (C. 2613-D), recientemente aprobada por las dos cámaras del Parlamento italiano, luego de un detenido proceso ${ }^{1}$. Se trataría de la reforma más ambiciosa de la Constitución de dicho país. Su entrada en vigor quedó pendiente de su ratificación en referéndum, ya que el

* Fernando Santaolalla López. Jefe de la Asesoría Jurídica. Senado. Calle Bailén, 3. 28071 Madrid. Email: fernando.santaolalla@senado.es

** Este artículo se escribió antes del referéndum de aprobación, que se acabó celebrando el 4 de diciembre de 2016. Como es sabido, se produjo un resultado claramente adverso a la reforma propuesta, que quedó así descartada. A pesar de ello creemos que los comentarios que siguen mantienen su vigencia. Entre otras cosas, no parece que la nueva regulación de los decretos-leyes fuese la determinante de este resultado.

${ }^{1}$ El Servicio de Estudios de la Cámara de Diputados ha publicado el texto comparativo a doble columna con el vigente. Véase en: http://documenti.camera.it/leg17/dossier/pdf/ac0500n.pdf 
art. 138, párrafo segundo, de la Constitución impone al afecto la aprobación por la mayoría de votos válidos ${ }^{2}$.

Entre las modificaciones más importantes cabe destacar el abandono del bicameralismo perfecto, de equiparación de Cámara de Diputados y Senado, en favor de un bicameralismo diferenciado, en el que la primera cámara, definida como representante de la nación (art. 55), asume una posición de primacía.

El Senado queda redefinido como cámara de representación de las instituciones territoriales (lo que recuerda a la fórmula de nuestro art. 69.1). En consecuencia se ajustan sus funciones (básicamente las relaciones con las regiones y con la Unión Europea). Sus componentes bajan drásticamente de 350 a 100.

En virtud de esta primacía, compete exclusivamente a la Cámara la formación de la relación de confianza con el Gobierno y el control correspondiente.

En cuanto a la potestad legislativa, se mantiene (art. 70 ap. 1) para las dos cámaras en las cuestiones más importantes (como la reforma y el desarrollo constitucional y otras). En el resto de materias, lógicamente mayoritarias, la Cámara asume en exclusiva su aprobación (art. 70 ap. 2), quedando el Senado reducido a una facultad de propuesta de modificaciones dentro de un plazo de hasta cuarenta días (art. 70 ap. 3), propuestas sobre las que decide la Cámara. Incluso, si el Senado no decide examinar el proyecto o transcurre el plazo sin manifestación al respecto, la ley queda en condiciones de ser promulgada. Esto último recuerda a lo establecido en el art. 90.2 de la Constitución española.

Se introduce un posible recurso previo de inconstitucionalidad contra las leyes que regulen la elección de los diputados y senadores, disponiendo el Tribunal Constitucional de treinta días para dictar sentencia (art. 73).

La reforma tiene también una repercusión muy destacada en el plano territorial. Por un lado, se suprimen las provincias. Por otro, se diseña un nuevo reparto funcional, con abandono del sistema de competencias concurrentes o compartidas para en su lugar implantar otro de competencias claramente separadas. La cláusula residual se dispone en beneficio de las regiones. A cambio, se introduce otra de supremacía de la ley estatal en materias exclusivas regionales cuando así lo exija la unidad jurídica o económica de la República.

Todos los aspectos mencionados son de enorme trascendencia y constituirán sin duda referencia para los españoles, especialmente ahora que tanto se habla de la reforma constitucional.

\footnotetext{
${ }^{2}$ Concretamente dispone: La legge sottoposta a referendum non è promulgata se non è approvata dalla maggioranza dei voti validi.
} 


\section{LA CUESTIÓN DE LOS DECRETOS LEYES: SIMILITUDES Y DIFERENCIAS}

Las líneas que siguen, lejos de abarcar la totalidad de la reforma, se centran en un particular aspecto, también con especial repercusión en España. Se trata de la disciplina de los decretos leyes.

En efecto, la legislación de urgencia se contempla en los dos países para atender exigencias iguales y con regulaciones en buena parte semejantes, seguramente debido a que el constituyente español de 1978 se inspiró en la Constitución italiana de $1947^{3}$. Por otro lado, este instrumento normativo ha generado en los dos países una problemática muy parecida, producto del abuso en su utilización.

La similitud entre las dos regulaciones se produce comparando los textos incluidos en el cuadro siguiente:

Art. 86 de la Constitución española

1. En caso de extraordinaria y urgente necesidad, el Gobierno podrá dictar disposiciones legislativas provisionales que tomarán la forma de Decretos-leyes y que no podrán afectar al ordenamiento de las instituciones básicas del Estado, a los derechos, deberes y libertades de los ciudadanos regulados en el Título I, al régimen de las Comunidades Autónomas, ni al Derecho electoral general.

2. Los Decretos-leyes deberán ser inmediatamente sometidos a debate y votación de totalidad al Congreso de los Diputados, convocado al efecto si no estuviere reunido, en el plazo de los treinta días siguientes a su promulgación. El Congreso habrá de pronunciarse expresamente dentro de dicho plazo sobre su convalidación o derogación, para lo cual el Reglamento establecerá un procedimiento especial y sumario.

3. Durante el plazo establecido en el apartado anterior, las Cortes podrán tramitarlos como proyectos de ley por el procedimiento de urgencia.
Art. 77 de la Constitución italiana

No podrá el Gobierno, sin delegación de las Cámaras, dictar decretos que tengan fuerza de ley ordinaria.

Cuando en casos extraordinarios de necesidad y de urgencia el Gobierno adopte, bajo su responsabilidad, medidas provisionales con fuerza de ley, deberá presentarlas el día mismo para su conversión a las Cámaras, las cuales, incluso hallándose disueltas, serán debidamente convocadas y se reunirán dentro de los cinco días siguientes.

Los decretos perderán todo efecto desde el principio si no fueren convertidos en ley dentro de los sesenta días de su publicación. Las Cámaras podrán, sin embargo, regular mediante ley las relaciones jurídicas surgidas en virtud de los decretos que no hayan resultado convertidos.

3 Así lo advertía ya A. Predieri, «El sistema de fuentes del derecho», en La Constitución española de 1978 Estudio sistemático, dir. A. Predieri y E. García de Enterría, Ed. Civitas, Madrid, 1980, p. 210. 
Como puede verse, el supuesto de hecho para la emanación de estos actos normativos es el mismo: la extraordinaria y urgente necesidad, expresión tras la que late la conciencia y el temor de los constituyentes a su abuso, como de hecho ha ocurrido en los dos países. Queremos decir que si se hubiese confiado en una aplicación rigurosa del procedimiento habría bastado hablar de «casos de necesidad» o «de urgencia». La enfática fórmula escogida (con el adjetivo «extraordinaria») revela la percepción de un problema y casi su aceptación como inevitable ${ }^{4}$.

Otro punto de coincidencia es lo que define al instrumento normativo: la adopción por el Gobierno de disposiciones con fuerza de ley, que se asumen como si hubiesen emanado del poder legislativo. Se trata de una normación extraordinaria ante un supuesto de hecho también extraordinario.

Asimismo esta legislación de urgencia coincide en sus efectos temporales en los dos países: se trata de disposiciones legislativas provisionales, en la expresión española, o de medidas provisionales, en la italiana. Por tanto en ambos casos se limita la vigencia temporal de estos decretos con fuerza de ley, conclusión lógica ya que en caso contrario se borraría la diferencia entre el poder legislativo en sentido estricto y el ejecutivo.

Y otra coincidencia: la provisionalidad de los decretos-leyes aparece asociada a la necesidad de su convalidación o conversión parlamentaria. Esto es, el poder legislativo mantiene su supremacía en la medida que decide si esa norma provisional estaba o no justificada. De admitirse esta circunstancia (convalidación o conversión) la norma provisional prolongaría sus efectos en el tiempo; de negarse, dicha norma perdería su vigencia. Este trámite se convierte en un procedimiento de control, en la medida que el Parlamento juzga y decide sobre el uso gubernamental de la legislación de urgencia.

Hasta aquí los aspectos comunes. Junto a ellos se presentan otros de signo discrepante. Veámoslos sucintamente.

La primera y una de las más importantes diferencia es que la conversión corresponde a las dos cámaras italianas, mientras que la convalidación la asume entre nosotros en exclusiva el Congreso de los Diputados.

En segundo lugar, la Constitución española veda cuatro amplias y significativas áreas (ordenamiento de las instituciones básicas del Estado; los derechos, deberes y libertades de los ciudadanos del Título I; el régimen de las Comunidades Autónomas y el Derecho electoral general) a la incidencia de los decretos-

${ }^{4}$ Por ejemplo, para Italia así lo reconocía C. Esposito, voz «Decreto-legge», en Enciclopedia del Diritto, Giuffré, Milán, tomo XI p. 832. 
leyes. Por el contrario, la solución italiana abre toda la reserva de ley a dicho instrumento normativo.

En tercer lugar, la conversión italiana se hace mediante ley formal (legge di conversione) mientras que la convalidación se efectúa en forma atípica, por simple acuerdo del Congreso de los Diputados. Algunos autores han querido hacer depender este rasgo del anterior, a saber, que la convalidación no podía hacerse por ley en España por cuanto solo participaba en la misma una de las dos cámaras que integran el poder legislativo. Este aspecto será comentado posteriormente.

Consiguientemente, en Italia se presenta un proyecto de ley de conversión, normalmente constituido por un solo artículo al que se anexa el texto del decreto-ley ${ }^{5}$. En cuanto tal, el proyecto sufre el procedimiento legislativo ordinario, caracterizado por intervención de una comisión que somete en su caso al pleno la propuesta de conversión, con o sin modificaciones ${ }^{6}$. Finalmente, el pleno aprueba o no el texto de la nueva ley y lo transmite a la otra cámara hasta que se produce una coincidencia entre ambas.

Mucho más precisa y considerada con el Parlamento es la Constitución italiana: el decreto-ley debe presentarse el mismo día de su promulgación en las cámaras y estas deben reunirse en los cinco días siguientes. En España no hay siquiera comunicación formal del decreto-ley, se deduce de su publicación en el BOE, y no se precisa el tiempo en que debe reunirse por vez primera el Congreso.

Otra diferencia es el plazo previsto para la intervención parlamentaria, dos meses en Italia y uno en España. Este aspecto sí que es dependiente del hecho de que allí participan las dos cámaras mientras que aquí lo hace una sola.

También resulta más precisa la Constitución italiana en lo referente a los efectos de la no conversión: pérdida con eficacia ex tunc de los efectos del decreto ley. La española no desciende a este extremo, dejándolo indeterminado. La importancia de este aspecto es mayor en la república transalpina, si se tiene en cuenta el considerable porcentaje (infra) de decretos-leyes no convertidos. Entre nosotros, la repercusión es sensiblemente menor habida cuenta del porcentaje ridículo de decretos-leyes no convalidados ${ }^{7}$.

5 En este sentido A. Mannino, Diritto parlamentare, Giuffré Editore, Milán, p. 250.

${ }^{6}$ Un resumen de este procedimiento ordinario en F. Santaolalla, 2015, Por un nuevo procedimiento legislativo, ed. Dykinson, Madrid, 2015, pp. 66-73.

7 Que sepamos tan solo dos decretos-leyes no han superado el trámite, y ello en circunstancias bastante atípicas. El primer caso fue el Real Decreto-ley 1/1979, aprobado cuando las Cortes estaban disueltas y que no fue convalidado por la Diputación Permanente del Congreso de los Diputados el 6 de febrero de 1979 (Diario de sesiones n. . 21, de 6 de febrero de 1979). El segundo fue el Real Decreto-ley 1/2006, de 20 de enero, por el que se modifican las tipos impositivos del impuesto sobre las labores del tabaco, según acuerdo del Pleno del Congreso de los Diputados 
Finalmente, la Constitución española admite algo innecesario: que los decretos-leyes se puedan tramitar luego de su convalidación por el procedimiento de urgencia. Decimos innecesario porque siempre habría resultado posible la formulación de un proyecto o proposición de ley con el mismo texto y su tramitación por el procedimiento de urgencia ${ }^{8}$. Nada de eso establece la Constitución italiana, aunque sí la posibilidad de regular las relaciones surgidas al amparo de un decreto-ley que luego no se convierte en ley y, por tanto, pierde retroactivamente su eficacia. Ante esta situación, razones de justicia pueden haber aconsejado prever una regulación para dichas relaciones nacidas durante su vigencia.

\section{LA APLICACIÓN PATOLÓGICA DE LOS DECRETOS LEYES}

En los dos países se ha dado una aplicación abusiva de los decretos leyes. A pesar de la prevención constitucional para limitarlos a concretas y excepcionales circunstancias, la realidad muestra un resultado muy distinto, hasta el punto de poderse hablar de abuso y crecimiento patológico de esta vía normativa.

Seguramente en los dos países los gobiernos no han podido resistirse a la tentación de utilizar un procedimiento que evita muchas críticas parlamentarias y que permite pasar disfrazadamente medidas que en otro contexto habrían suscitado oposición.

Desde luego, la palma en este ranking sui generis se la lleva Italia, donde el problema se ha mantenido en unos términos inquietantes. En total, para el periodo 1 enero 1979 a 31 de diciembre de 2015 (el mismo que luego se utiliza para España) se cuentan nada menos que ¡2.996 decretos leyes!'?

del día 9 de febrero de 2006 (Diario de sesiones n. ${ }^{\circ}$ 148, de 9 de febrero de 2006). Al parecer se debió a un error en la votación.

${ }^{8}$ El carácter superfluo del procedimiento del art. 86.3 ha sido admitido por numerosos comentaristas. Así J. Salas en Los decretos-leyes en la Constitución española de 1978, Ed. Civitas, Madrid, 1979, pp. 104 y s.; I. De OTTO en Derecho constitucional sistema de fuentes, Ed. Ariel, Barcelona, 1987, p. 208.; P. SANTOlaya en El régimen constitucional de los decretos-leyes, Ed. Tecnos, Madrid, 1988, pp. 200 y s.; I. Astarloa en Comentarios a la Constitución española de 1978, dir. O. Alzaga, Cortes Generales Editoriales de Derecho Reunidas, Madrid, 1996, t VII p. 226.

9 Resultado obtenido introduciendo estas dos referencias temporales en:

http://www.normattiva.it/do/ricerca/avanzata/aggiornamenti/0 
El siguiente cuadro también es muy revelador sobre el número de decretos leyes a partir del año 1997 en Italia ${ }^{10}$ :

\begin{tabular}{|c|c|c|c|}
\hline Ańo & N.o $^{\circ}$ D-L & Ańo & N.o D-L \\
\hline 1997 & 44 & 2006 & 32 \\
\hline 1998 & 29 & 2007 & 21 \\
\hline 1999 & 42 & 2008 & 38 \\
\hline 2000 & 36 & 2009 & 17 \\
\hline 2001 & 50 & 2010 & 22 \\
\hline 2002 & 44 & 2011 & 16 \\
\hline 2003 & 48 & 2012 & 32 \\
\hline 2004 & 42 & 2013 & 26 \\
\hline 2005 & 37 & $2014($ en-feb) & 4 \\
\hline
\end{tabular}

En España las cifras son sensiblemente menores, sin que ello suponga rebajar su gravedad. Desde la vigencia de la Constitución (enero de 1979) hasta diciembre de 2015 se habrían dictado 518 decretos leyes. Reproducimos el cuadro con el número anual que tomamos de L. Martín Rebollo ${ }^{11}$ :

Número de decretos-leyes por años:

\begin{tabular}{|c|c|c|c|c|c|c|c|c|c|}
\hline Ańo & N.o DL $^{*}$ & Ańo & N.o $^{\circ}$ DL & Ańo & N.o DL $^{\circ}$ & Ańo & N.o DL & Ańo & N.o DL \\
\hline 1979 & 22 & 1987 & 7 & 1995 & 12 & 2003 & 7 & 2011 & 20 \\
\hline 1980 & 16 & 1988 & 7 & 1996 & 17 & 2004 & 11 & 2012 & 29 \\
\hline 1981 & 19 & 1989 & 7 & 1997 & 29 & 2005 & 16 & 2013 & 17 \\
\hline 1982 & 26 & 1990 & 6 & 1998 & 20 & 2006 & 13 & 2014 & 17 \\
\hline 1983 & 9 & 1991 & 5 & 1999 & 22 & 2007 & 11 & 2015 & 12 \\
\hline 1984 & 15 & 1992 & 6 & 2000 & 10 & 2008 & 10 & & \\
\hline 1985 & 8 & 1993 & 22 & 2001 & 16 & 2009 & 14 & & \\
\hline 1986 & 3 & 1994 & 13 & 2002 & 10 & 2010 & 14 & & \\
\hline
\end{tabular}

Según dicho autor, la media anual sería de casi 14 decretos leyes, pero con el importante matiz de tender a incrementarse con el paso del tiempo, al igual que el porcentaje que los mismos representan frente a las leyes ordinarias aprobadas por las Cortes, aspectos ambos en los que se aprecia también una coincidencia básica con lo ocurrido en Italia.

${ }^{10}$ Fuente: Senato XVII Legislatura Decretazione d'urgenza e conversione: la recente giurisprudenza costituzionale, marzo 2014, n. 111, en http://www.senato.it/service/PDF/PDFServer/BGT/00750416.pdf.

${ }^{11}$ Véase Uso y abuso del Decreto-Ley. (Un análisis empírico), en Revista española de Derecho Administrativo, 2015, núm. 174 (octubre-diciembre 2015). Incluimos en 2015 el número final de decretos leyes, 12 en lugar de 9 que recoge este autor. 


\section{LAS DISTINTAS SITUACIONES DE HECHO ENTRE ITALIA Y ESPAÑA}

Aun compartiendo tantas circunstancias legales y fácticas los dos países, el destacado exceso de los decretos-leyes italianos frente a los españoles -la diferencia que va de 2.996 a 518- se relaciona con particulares condiciones del país transalpino.

En primer lugar debe destacarse la proporcionalidad pura que durante varios decenios dominó el escenario electoral italiano, lo que se traducía en mayorías pluripartidistas, débiles y propensas a las crisis. La reforma en pro de un sistema mixto $^{12}$ de las leyes n. 276 y 277 , de 4 agosto 1993 , solo revertió parcialmente esta situación: a partir de la XII legislatura (1994-96) se concentró el voto en menos candidaturas electorales, pero al basarse estas no pocas veces en coaliciones de diversos partidos al final no pudo evitarse la división de las cámaras en diversos grupos parlamentarios, sin que ninguno ostentase la mayoría absoluta ${ }^{13}$.

De este modo, indirectamente, se favorecía que gobiernos apoyados en coaliciones acudiesen a la legislación de urgencia, como medio de evitar sobresaltos en lo que en otro caso habría necesitado la tramitación de un proyecto de ley.

A lo anterior, debe añadirse una vida parlamentaria libre y abierta, con numerosas posibilidades de intervención y crítica para los grupos y los parlamentarios individuales, lo que sin duda tenía la contrapartida de hacer más difícil la ejecución del programa político del Gobierno en las cámaras.

Particular mención merece en este sentido el voto secreto que estuvo vigente hasta la reforma de los reglamentos parlamentarios en 1988, lo que favorecía el obstruccionismo, llegando hasta el extremo de que el Gobierno no pudiese controlar el voto de sus propios diputados y senadores ${ }^{14}$.

Todo ello impulsaba, como decíamos, a los gobiernos a valerse de la legislación de urgencia como vía más segura de adopción de medidas, incluso plantean-

12 Según este nuevo sistema, las dos asambleas pasaban a elegirse en sus tres cuartas partes en distritos uninominales y sufragio mayoritario. El cuarto restante se elegía por un sistema proporcional en 26 circunscripciones en la Cámara, mientras que en el Senado lo hacía indirectamente por los grupos parlamentarios en proporción al número de escaños obtenidos en el primer cupo en la región respectiva. Véase http://www.camera.it/leg17/512? conoscerelacamera $=41$

13 Fuente: http://leg15.camera.it/organiparlamentarism/239/260/documentoxml.asp

${ }_{14} \mathrm{Al}$ respecto puede verse A. Mannino, Diritto parlamentare, Giuffré Editore, Milán, 2010, pp. 205-213. 
do cuestiones de confianza - no previstas en la Constitución-sobre los proyectos de conversión ${ }^{15}$.

Pero ni siquiera así, y a diferencia del caso español, el decreto-ley representaba una verdadera alternativa. Las circunstancias antedichas llevaban también a la posible no conversión en el plazo constitucional de 60 días. En esta tesitura ${ }^{16}$, y ante el mandato del art. 77 de pérdida retroactiva de efectos, el Gobierno se veía impelido a aprobar segundos y sucesivos decretos-leyes de prórroga del no convertido a tiempo. Aparecían así las cadenas de decretos leyes, ¡con reiteración del mismo contenido hasta 15 y 20 veces ${ }^{17}$ !

Así se derivó en un crecimiento elefantiásico de este procedimiento normativo $^{18}$.

\section{LA RESPUESTA DE LA CORTE CONSTITUCIONAL}

Ante este panorama, el Tribunal Constitucional italiano intentó poner algunos límites, punto que también coincide con lo acontecido entre nosotros. La sentencia n. 29 de 1995 admitió que los requisitos de extraordinaria y urgente necesidad podían ser objeto de control. La sentencia n. 360 de 1996 declaró la ilegitimidad de la reiteración de decretos leyes, bien que de un modo muy matizado $^{19}$. Y la n. 171 de 2007 anuló por primera vez una disposición de un decreto-ley por evidente falta de los presupuestos constitucionales.

15 Véase A. Mannino, Diritto parlamentare, pp. 305 y ss, L. Gianniti y N. Lupo, Corso di diritto parlamentare, Ed. Il Mulino, 2013, pp. 215 y s.

${ }_{16} \mathrm{M}$. Esposito califica de degenerada esta tesitura. De otra parte, afirma que la no conversión de un decreto-ley afecta a la relación de confianza del Parlamento con el gobierno. Véase «Decreto-legge, indirizzo político e rapporto de fiducia», en I Rapporti tra parlamento e governo attraverso le fonti del diritto: atti del convegno di Napoli svoltosi nei giorni 12 e 13 maggio 2000, G. Giappicheli Editore, Torino, 2001, v. I., pp. 167 y ss.

17 Véase en este sentido V. De Ciolo y L. Ciaurro, Il diritto parlamentare nella teoría en nella pratica, Giuffré Editore, Milán, 2013, pp. 635 y s.

18 Señala A. MANNiNo que en esta alteración fáctica de la regulación constitucional estaban interesados todos los operadores políticos: el gobierno y la mayoría por cuanto les facultaba para alcanzar rápidamente los intereses perseguidos; la oposición, y especialmente los grupos de izquierda, por cuanto la amenaza de impedir la conversión en el plazo constitucional le permitía exigir cambios en el contenido de la norma a convalidar, y las fuerzas sociales interesadas por cuanto podían obtener la entrada en vigor inmediata de una norma. Véase Diritto..., ob. cit., pp. 261 y s.

19 Según A. Simoncini, la reiteración sería legítima cuando se diese una de estas dos hipótesis: a) que el gobierno base el nuevo decreto-ley en nuevos presupuestos extraordinarios o b) que se introduzcan contenidos normativos nuevos. En todo caso, el posible vicio de la reiteración 
Se reformaron entonces los reglamentos del Senado (en 1988) y de la Cámara (en 1997): en el primer caso para obligar a examinar los requisitos establecidos en la legislación vigente y los presupuestos de necesidad y urgencia; en el segundo para disponer un informe del Comité para la legislación sobre el cumplimiento de los requisitos legales.

Sin embargo, tales medidas no impidieron la proliferación de decretos-leyes, incluida su reiteración ${ }^{20}$. Algunos autores hallan una explicación en el hecho de que la verificación de la extraordinaria necesidad y urgencia no podría hacerse en base a criterios automáticos o textuales ${ }^{21}$. Para otros, su conversión por el Parlamento obedecería a que, siendo esta institución un órgano político, resultaría falaz pensar que el mismo pudiese distinguir entre la valoración de la legitimidad constitucional de un decreto-ley y sus aspectos de fondo ${ }^{22}$.

Ante esta realidad, no es de extrañar que hayan sucedido otros pronunciamientos del Tribunal Constitucional, con el mismo propósito de refrenar el uso injustificado de la legislación de urgencia ${ }^{23}$. Continuando en la línea de las anteriores, la sentencia n. 128 de 2008 confirmó que los presupuestos de hecho del decreto-ley serían controlables por el propio Tribunal, añadiendo que su ausencia viciaría también la subsiguiente ley de conversión. Por su parte, la sentencia n. 22 de 2012 dio una aldabonazo frente a los decretos-leyes de contenido heterogéneo, exigiendo que todas sus disposiciones obedezcan a una extraordinaria necesidad y urgencia. Por tanto, habría una necesidad de homogeneidad, que igualmente sería exigible a la ley de conversión. Respecto a esto último, cabe destacar que los reglamentos de ambas cámaras prohíben la presentación de enmiendas y propuestas que sean ajenas al tema debatido.

Posteriormente, la sentencia n. ${ }^{\circ} 220$ de 2013 estableció la inadecuación del decreto-ley para abordar reformas institucionales perdurables en el tiempo (como la de los entes locales), que excedan de lo meramente puntual, y que no impliquen medidas que sean de inmediata aplicación.

quedaría sanado cuando la ley de conversión asuma la regulación del gobierno. Véase de este autor Le funzioni del decreto-legge, Giuffré Editore, Milán, 2010, pp. 22 y s.

${ }^{20}$ En la XV legislatura (abril 2006-abril 2008) el porcentaje de decretos-leyes sobre leyes aprobadas fue del 30 por ciento. Fuente: A. Mannino Diritto..., p. 268.

${ }^{21}$ Así lo afirman A. Mannino, Diritto..., pp. 264-66, y V. De Ciolo y L. Ciaurro, Il diritto..., p. 641.

22 En este sentido, L. Gianniti y N. Lupo, Corso di diritto parlamentare, Ed. Il Mulino, 2013, p. 244.

${ }^{23}$ Fuente: Senato XVII Legislatura, Decretazione d'urgenza e conversione: la recente giurisprudenza costituzionale, marzo 2014, n. 111, en http://www.senato.it/service/PDF/PDFServer/ BGT/00750416.pdf. 
Finalmente, cabe reseñar la sentencia n. 32 de 2014, centrada en la ley de conversión. En concreto, declaró la inconstitucionalidad de unos artículos introducidos por vía de enmienda en el entonces proyecto de ley y que daría lugar a la Ley n. 49 de 2006. Según el Tribunal, habría un nexo de interrelación entre el decreto-ley y la ley de conversión, sometida a un procedimiento simplificado, lo que impediría su apertura a cualquier contenido ajeno al Decreto-ley. De lo que se sigue la exigencia de homogeneidad material entre ambas normas.

Es posible que la actitud beligerante del Tribunal Constitucional italiano haya conducido a una cierta disminución de la legislación de urgencia en los últimos años, como se desprende del cuadro antes incluido. A pesar de ello, su número sigue siendo elevado, sin correspondencia con las extraordinarias circunstancias que teóricamente rigen para su aprobación ${ }^{24}$.

\section{LA REFORMA DEL ARTÍCULO 77}

A la vista de estos problemas, no puede extrañar que uno de los aspectos de la reforma constitucional aprobada inicialmente en abril de 2016 haya sido precisamente el de los decretos-leyes.

Concretamente, el artículo 77 sufre una importante modificación, cuyos puntos básicos serían los siguientes ${ }^{25}$ :

${ }^{24}$ Véase en este sentido el reciente Camera dei Deputati Osservatorio sulla legislazione Rapporto 2014, especialmente pp. 448 y s y 459 y s. . Accesible en: http://www.camera.it/application/ xmanager/projects/leg17/file/documenti/TOMO_II.aggiornato_31_dicembre.pdf

${ }^{25}$ El nuevo texto es el siguiente:

Il Governo non può, senza delegazione delle Camere, emanare decreti che abbiano valore di legge ordinaria. Il Governo non può, senza delegazione disposta con legge, emanare decreti che abbiano valore di legge ordinaria.

Quando, in casi straordinari di necessità e d'urgenza, il Governo adotta, sotto la sua responsabilità, provvedimenti provvisori con forza di legge, deve il giorno stesso presentarli per la conversione alla Camera dei deputati, anche quando la funzione legislativa è esercitata collettivamente dalle due Camere.

La Camera dei deputati, anche se sciolta, è appositamente convocata e si riunisce entro cinque giorni.

I decreti perdono efficacia sin dall'inizio, se non sono convertiti in legge entro sessanta giorni dalla loro pubblicazione o, nei casi in cui il Presidente della Repubblica abbia chiesto, a norma dell'articolo 74, una nuova deliberazione, entro novanta giorni dalla loro pubblicazione. La legge può tuttavia regolare i rapporti giuridici sorti sulla base dei decreti non convertiti.

Il Governo non può, mediante provvedimenti provvisori con forza di legge: disciplinare le materie indicate nell' articolo 72, quinto comma, con esclusione, per la materia elettorale, della disciplina dell'organizzazione del procedimento elettorale e dello svolgimento delle elezioni; reiterare disposizioni adottate con decreti non convertiti in legge e regolare i rapport giuridici sorti sulla base dei medesimi; ripristinare l'efficacia di norme 
- La presentación del proyecto de ley de conversión del decreto-ley debe producirse necesariamente en la Cámara de Diputados, aunque la función legislativa corresponda conjuntamente a las dos cámaras.

- Exclusión de las siguientes materias y regulaciones al decreto-ley: leyes en materia constitucional y electoral, pero exceptuando de esta última a la organización del procedimiento electoral y desarrollo de las elecciones; leyes de conversión de decretos leyes; leyes de autorización de tratados internacionales; leyes de presupuesto y de gasto (todas ellas mencionadas en el art. 72); reiteración de disposiciones incluidas en decretos-leyes no convertidos y regulación las relaciones jurídicas surgidas de los mismos, y restablecimiento de eficacia de normas que el Tribunal Constitucional hubiese declarado ilegítimas por vicios no procedimentales.

- Los decretos-leyes deben limitarse a medidas de aplicación inmediata y contenido específico, homogéneo y correspondiente a su título.

- Desdoblamiento de la intervención de las cámaras en el trámite de convalidación, paralelo al de división de la potestad legislativa entre un procedimiento bicameral y otro unicameral: si el decreto-ley incide en materias en las que el Senado conserva su plena potestad legislativa, el proyecto de ley de conversión sufre la tramitación correspondiente, con necesaria aprobación por las dos cámaras; cuando, por el contrario, el decreto-ley incide en las materias en las que la Cámara de Diputados asume en exclusiva su aprobación (llamadas leyes monocamerales participadas), el proyecto de ley de conversión queda sometido a un procedimiento estricto en el Senado: puede examinarlo dentro de los treinta días siguientes a su presentación en la Cámara, pero las propuestas de modificación debe aprobarlas en los diez días siguientes a la fecha de su transmisión, sin poder superar los 40 días desde su presentación. Sobre estas posibles propuestas de modificación (enmiendas) decide luego la Cámara, como en el procedimiento legislativo ordinario.

- Durante la tramitación del proyecto de ley de conversión no se pueden aprobar disposiciones extrañas a su objeto y finalidad.

di legge o di atti aventi forza di legge che la Corte costituzionale ha dichiarato illegittimi per vizi non attinenti al procedimento.

I decreti recano misure di inmediata applicazione e di contenuto specifico, omogeneo e corrispondente al titolo.

L'esame, a norma dell'articolo 70, terzo e quarto comma, dei disegni di legge di conversione dei decreti è disposto dal Senato della Repubblica entro trenta giorni dalla loro presentazione alla Camera dei deputati. Le proposte di modificazione possono essere deliberate entro dieci giorni dalla data di trasmissione del disegno di legge di conversione, che deve avvenire non oltre quaranta giorni dalla presentazione.

Nel corso dell'esame di disegni di legge di conversione dei decreti non possono essere approvate disposizioni estranee all'oggetto o alle finalità del decreto. 
Como puede verse, se produce una parcial pero importante convergencia con el régimen de los decretos-leyes en España: el hecho de vedarse su uso para la regulación de cuestiones constitucionales y electorales recuerda claramente lo excluido en el art. 86.1 de nuestra Constitución (instituciones básicas del Estado, los derechos, deberes y libertades de los ciudadanos regulados en el Título I, régimen de las Comunidades Autónomas, Derecho electoral general). Merman así las ocasiones para la utilización injustificada de los decretos-leyes.

Junto a lo anterior, llama positivamente la atención la exigencia de que la legislación de urgencia se limite a medidas específicas y homogéneas, evitando que la ocasión se aproveche para regular disimuladamente aspectos que poco o nada tienen que ver con la urgente necesidad. Y en el mismo sentido no podrá aprovecharse la premura de los plazos del trámite parlamentario para incluir regulaciones ajenas al ámbito del decreto-ley. Esta previsión es reveladora de la preocupación por la técnica normativa en la reforma italiana, sin que el sustantivo «técnica» permita ignorar su significativa repercusión política. Cabe presumir que la jurisprudencia constitucional, antes resumida, ha influido en estas previsiones.

De modo concordante, el primer apartado del nuevo art. 70 establece que las leyes de aprobación conjunta por las dos cámaras - sin duda las más importantesdeban contar con un objeto propio y su derogación o reforma sujetarse a las normas incluidas en el mismo, lo que parece excluir leyes de contenido heterogéneo.

Por otro lado, el mantenimiento del plazo de 60 días para la conversión en un procedimiento en el que el Senado queda habitualmente marginado hace presumible que la Cámara pueda aprobar oportunamente la ley de conversión, evitando los casos de caducidad de decretos-leyes no convertidos, y lo que fue consecuencia suya, su reiteración ${ }^{26}$.

También resulta loable excluir del decreto-ley a las normas que no sean de aplicación inmediata, pues precisamente esta circunstancia hace presumir que no conllevan la urgente necesidad.

${ }^{26}$ No obstante, los plazos previstos para el Senado podrían producir problemas. Véase al respecto T. GuARnier, Le leggi a prevalenza Camara nel disegno di revisione costituzionale federalismi. it Rivista di diritto pubblico italiano comoparato e europeo, 1 junio 2016, p. 16. Por su parte, R. DicKMANN se refiere a la intervención de los dos presidentes de las cámaras ante las posibles cuestiones de competencias entre ellas: Le cuestioni di competenza nel bicameralismo legislativo asimmetrico. Alcuni spunti critici, en federalismi.it Rivista di diritto pubblico italiano comparato e europeo 1 junio 2016 pp. 7 y s. 
Es imposible predecir el éxito de estas formulaciones. Pero lo que no cabe duda es que, al menos, constituyen un serio intento de ceñir la legislación de urgencia a lo que la justifica, recortando las ocasiones de abuso.

\section{LECCIONES QUE PUEDEN EXTRAERSE PARA EL CASO ESPAÑOL}

La reforma constitucional italiana de los decretos-leyes, con sus en general esperanzadores aportes, ofrece algunas lecciones para la teoría y práctica españolas.

Nos vamos a referir a tres aspectos: por un lado, la forma de la convalidación de los decretos-leyes; por otro, el control de los hechos determinantes o valoración de la urgente necesidad, y, finalmente, otros límites materiales y formales.

\section{Forma de la convalidación de los decretos-leyes}

A. Forma atípica actual de convalidación

Como es sabido, los decretos-leyes se convalidan en España por un acto innominado y atípico (acuerdo de convalidación) que como tal se publica en el $B O E^{27}$.

La cuestión de la forma de la convalidación parecería un detalle menor, solo relativa a la estética del acto en cuestión. Pero no es tal. Semejante informalismo ha causado numerosas dudas doctrinales y prácticas sobre el alcance de la decisión del Congreso de los Diputados.

Así, recientemente L. Martín Rebollo ${ }^{28}$ y M. Aragón Reyes ${ }^{29}$ se han visto inducidos -con una argumentación no exenta de lógica- a la siguiente conclusión: si el decreto-ley es una disposición provisional, según establece el art. 86.1 de la Constitución, y si la convalidación del Congreso no es una ley, no se comprendería que perviva indefinidamente en el tiempo una norma que procede del poder ejecutivo y que incide en la reserva de ley. Resultaría incomprensible que una

27 Así: Resolución de ... de ... de ..., del Congreso de los Diputados, por la que se ordena la publicación del Acuerdo de convalidación del Real Decreto-ley ... Sigue el cuerpo del acuerdo en el que se reitera la fecha en que el decreto-ley ha sido convalidado, se proclama que se ordena la publicación para general conocimiento y concluye con la fecha y la firma del Presidente del Congreso.

${ }^{28}$ Véase Uso y abuso del Decreto-Ley. (Un análisis empírico), en Revista española de Derecho Administrativo, 2015, núm. 174 (octubre-diciembre 2015), apartado 4 C.

29 Véase Uso y abuso del Decreto-Ley. Una propuesta de reinterpretación constitucional, Real Academia de Jurisprudencia y Legislación, Madrid, 2016, pp. 168 y s. 
norma calificada de provisional pueda mantenerse indefinidamente, como si de una auténtica ley se tratase. Por eso, concluyen ambos autores, la forma de resolver esa contradicción es imponer con carácter general que todos los decretos-leyes se tramiten tras su convalidación por el procedimiento del art. 86.3. Aparecería entonces una ley que sustituiría al decreto ley provisional, restableciendo el equilibrio perdido.

Ciertamente la convalidación de los decretos-leyes no se hace en España mediante ley. Pero la cuestión es: ¿debería lege ferenda hacerse así para que el sistema ganase en coherencia y eficacia?

M. Aragón Reyes ${ }^{30}$, al igual que L. Martín Rebollo, aduce como principal argumento en contra que el acto de convalidación del art. 86.2 es un acto unicameral mientras que la potestad legislativa corresponde a las dos cámaras de las Cortes Generales. Por eso, a su juicio, la convalidación no podría hacerse con forma de ley.

De este modo se reabre la polémica de los primeros años en la que algunos autores defendieron la forma de ley para la convalidación y otros la rechazaban. Entre los primeros, E. García de Enterría y T. R. Fernández escribieron que el decreto-ley convalidado quedaría convertido en Ley que debería sancionarse y promulgarse como tal ${ }^{31}$. Por su parte, J. Salas defendió que la convalidación debería hacerse por una ley de artículo único y de aprobación unicameral, añadiendo con mucha sensatez que no dejaría de ser paradójico que la derogación de un acto con fuerza de ley pudiese hacerse por algo que no fuese una ley ${ }^{32}$. Modestamente también nosotros hemos respaldado esta interpretación ${ }^{33}$.

Sin embargo, otros autores, con argumentos parecidos a los que hoy sostienen L. Martín Rebollo ${ }^{34}$ y M. Aragón Reyes, se mostraron contrarios a la veste de ley. Así, J. Jiménez Campo ${ }^{35}$ adujo que la convalidación no sería una ley pero sí

30 Véase M. Aragón Reyes, Uso y abuso del Decreto-Ley, ob. cit., pp. 168 y s.

31 Véase E. García de Enterría y T. R. Fernández, Curso de Derecho Administrativo, I, Ed. Civitas, Madrid, 2002, pp. 147 y s

32 Véase J. SALAs, Los decretos-leyes en la Constitución española de 1978, Ed. Civitas, Madrid, 1979, pp. 92 y s. También, sin duda influido por el precedente de su país, A. Predieri postuló lo mismo en «El sistema de fuentes del derecho», en La Constitución española de 1978 Estudio sistemático, dir. A. Predieri y E. García de Enterría, Ed. Civitas, Madrid, 1980, p. 183.

33 Véase F. Santaolalla, Derecho parlamentario español, Ed. Dykinson, Madrid, 2015, pp. 400 y s.

34 Véase Uso y abuso del Decreto-Ley. (Un análisis empírico), en Revista española de Derecho Administrativo, 2015, núm. 174 (octubre-diciembre 2015), apartado 4 C.

35 Véase J. Jiménez Campo, «Las Diputaciones Permanentes y el control sobre el Decretoley», en Revista de Derecho Político, núm. 15 (1982), p. 45. Por su parte, P. Santolaya mantuvo implícitamente esta misma interpretación, si bien admitió que el trámite del art. 86 ap. 3 significaría la tramitación de ley en un mes, con lo cual podría haberse dado la convalidación por ley. 
una resolución del Congreso con fuerza de ley, por una doble razón: ser unicameral y la desvirtuación que en caso contrario se produciría del art. 86.1 de la Constitución y sus materias excluidas. I. de Otto ${ }^{36}$ escribió que la convalidación no convertía al decreto-ley en ley, sino que seguía siendo lo primero. Por su parte, I. Astarloa ${ }^{37}$ defendió que el acto convalidación no es una ley formalmente ni materialmente, pues es decidido por una sola cámara y su contenido no es directamente regulador de situaciones jurídicas. De modo parecido, para A. M. Carmona la convalidación operaría sobre normas ya vigentes y su resultado sería una disposición con fuerza de ley, en ningún caso una ley formal ${ }^{38}$.

La jurisprudencia constitucional se ha inclinado también por esta interpretación que estimamos defectuosa. Una larga lista de sentencias (29/1982, de 31 de mayo, 6/1983, de 4 de febrero, 111/1983 de 2 de diciembre, y 155/2005, de 9 de junio) rechaza que el acuerdo de convalidación previsto en el artículo 86.2 C. E. convierta al Decreto-ley correspondiente en ley formal del Parlamento.

Sin embargo, resulta incoherente afirmar que la convalidación del Congreso no cambia la naturaleza jurídica del Decreto-ley, que no se transformaría en ley, y al mismo tiempo defender que supone el cumplimiento de un requisito del que depende la pervivencia en el tiempo «con fuerza y valor de ley» de la disposición gubernamental.

Realmente, si la convalidación, por un lado, la hace un órgano legislador y, por otro, supone mantener la fuerza y valor de ley del decreto originario, no comprendemos la oposición a admitir su condición de ley formal. En otras palabras, no se explica cuál sería el daño que depararía la utilización de esta forma si se acepta que la convalidación comporta en todo caso esos efectos. De influir en algo esa forma sería más bien para reforzar esa fuerza y valor de ley que nadie discute.

No obstante, añadió que razones prácticas justificaban la acumulación de los dos trámites, admitiendo tácitamente que la convalidación por el Congreso ex art. 86.2 fuese sin forma de ley. Véase El régimen constitucional de los decretos-leyes, Ed. Tecnos, Madrid, 1988, pp. 200 y s.

36 Véase I. De Oтто, Derecho constitucional sistema de fuentes, Ed. Ariel, Barcelona, 1987, p. 202.

37 Véase I. Astarloa Huarte-Mendicoa, artículo 86, en Comentarios a la Constitución española de 1978, dir. O. Alzaga, Cortes Generales Editoriales de Derecho Reunidas, Madrid, 1996, t VII p. 233.

38 Véase A. M. Carmona, La configuración constitucional del decreto-ley, CEPC, Madrid, 1997, p. 260. Añadía esta autora que la convalidación sería un acto bifronte, de control que a su vez genera efectos legislativos. 
B. Consideración de esta forma a la vista de la reforma constitucional italiana

En todo caso, lo que ahora queremos resaltar es que la reforma constitucional italiana ha privado en buena parte de fundamento a esas consideraciones en las que se basaba la oposición a la forma de ley: el proyectado art. 77 admite implícitamente que la convalidación se haga por una sola cámara, al tiempo que se mantiene esta forma. De hecho la documentación oficial sobre el nuevo procedimiento legislativo habla de «procedimiento legislativo monocameral» ${ }^{39}$, siendo esta misma interpretación compartida por diversos estudiosos ${ }^{40}$.

Además, esta regulación coincide con la nueva previsión general (art. 70), que distingue entre leyes que necesitan la aprobación de las dos cámaras y leyes cuya aprobación corresponde en exclusiva a la Cámara de Diputados, probablemente las más numerosas. Se confirma así la posibilidad de leyes unicamerales en sistemas bicamerales. Por lo demás no es el primer caso en que se concentra la potestad legislativa en una de las dos asambleas, con exclusión de la otra: la Constitución francesa de 1946, en su redacción vigente hasta 1954, reservó a la Asamblea Nacional la votación y aprobación de las leyes, reduciendo al Consejo de la República o segunda cámara a una función consultiva.

Por tanto, es perfectamente posible que una ley se apruebe por una de las dos asambleas que integran el Parlamento bicameral de un país. Que lo anterior no resulte lo más habitual no significa que sea incompatible con el sistema parlamentario.

C. Posible nueva regulación de la convalidación por el Congreso

El error de nuestro constituyente fue acortar el plazo de convalidación que constaba en la Constitución italiana de 60 a 30 días, lo que ciertamente dificultaba que el trámite se verificase en las dos Cámaras de las Cortes. Una vez limitado el trámite al Congreso, y aunque la Constitución no se manifestaba sobre su forma, se posibilitaba en alguna medida la fórmula atípica que luego se impuso. Pero tampoco habría resultado imposible una ley de convalidación en

39 Véase: http://www.camera.it/ XVII Legislatura/Documenti/temi dell'attività parlamentare/Riforme costituzionali.

40 En este sentido puede verse T. Guarnier, Le leggi a prevalenza Camara nel disegno di revisione costituzionale federalismi.it, Rivista di diritto pubblico italiano comoparato e europeo, 1 junio 2016, por su parte, R. DickMAnN se limita a distinguir ente leyes necesariamente bicamerales y leyes eventualmente bicamerales, centrándose en los problemas que puede suscitar el deslinde de ambas reservas: Osservazioni sulla nova organizacione del proceso legislativo dopo la riforma costituzionale federalismi.it Rivista di diritto pubblico italiano comoparato e europeo, 24 febrero 2016. 
ese plazo. Piénsese que la importante reforma del art. 135 de la Constitución, que incluyó presentación de enmiendas, se verificó en un plazo inferior a 30 días: habiéndose presentado la proposición de reforma en el Congreso de los Diputados el 26 de agosto de 2011 quedó aprobada por el Senado el 7 de septiembre siguiente. Si reforma de tanta trascendencia se tramitó en trece días, no parece que otra pueda ser la consecuencia para leyes de menor envergadura.

En cuanto a la ordenación actual del debate de convalidación, cabe recordar que, según el art. 151.2 y el concordante 74.2 del Reglamento del Congreso, consiste en una primera intervención de un miembro del Gobierno, sobre las razones de la promulgación del decreto-ley, seguido de turnos de portavoces de quince minutos cada uno. En la práctica los turnos se consumen por los grupos yendo de menor a mayor, por lo que cierra el portavoz del grupo gubernamental. Por el grupo mixto suelen intervenir varios diputados en nombre de los distintos partidos que lo integran.

Esta regulación ha determinado un debate indiferenciado, sin separación de los distintos aspectos que puede contener un decreto-ley.

Frente a este modelo, la fórmula que propugnamos -convalidación por leyaportaría ventajas no solo estéticas o formales, sino que podrían mejorar la funcionalidad del sistema democrático: la tramitación de un proyecto de ley de convalidación aumentaría las posibilidades de control y participación de las fuerzas políticas, especialmente de la oposición ${ }^{41}$. En un lugar de ese acto único y fugaz sobre la totalidad del decreto-ley ${ }^{42}$, esta vía permitiría presentar vía enmienda alternativas a todos y cada uno de los artículos, su discusión y votación separada ${ }^{43}$. Debería dictaminarse por una comisión y luego debatirse y votarse en el pleno. Por tanto, no se trata de un mero formalismo de fachada sino de un

${ }^{41}$ En este sentido puede verse A. Carmona, La configuración constitucional..., ob. cit., pp. 232-238.

${ }^{42}$ En la práctica, y en consonancia con esta ordenación tan taxativa, no es mucho el tiempo que se dedica a este trámite. Por solo citar unos ejemplos recientes, el debate del Decreto-Ley 1/2012, de 27 de enero, duró dos horas 20 minutos; el del Decreto-Ley 13/2012, de 30 de marzo, una hora 43 minutos; el del Decreto-Ley 17/2013, de 27 de diciembre, una hora y 41 minutos; el del Decreto-Ley 11/2015, 53 minutos; el del Decreto-Ley 1/2014, de 24 de enero, dos horas y el del Decreto-Ley 12/2015, de 30 de octubre, una hora y 10 minutos.

Fuente de lo anterior:

http://www.congreso.es/portal/page/portal/Congreso/Congreso/Intervenciones?_pir ef73_1335415_73_1335414_1335414.next_page=/wc/enviarCgiBuscadorIntervenciones

43 Así se hace en Italia. Véase V. Di Cıolo, Questioni in tema di Decreti-Legge, Ed. Giuffrè, Milán, 1970, pp. 357 y s. Más recientemente puede verse el comentario de la regulación reglamentaria en V. De Ciolo y L. Ciaurro, Il diritto parlamentare nella teoría en nella pratica, Giuffré Editore, Milán, 2013, pp. 639 y s. Asimismo A. Mannino, ob. cit., p. 258 
tema en el que forma y fondo van estrechamente unidos. Una tramitación más sustanciada permitiría un mayor control de las distintas disposiciones del decreto-ley.

El proyectado art. 72 de la Constitución italiana confirma que lo que comentamos no es algo baladí, pues somete estos proyectos de ley de conversión a la tramitación ordinaria reservada para las cuestiones más graves ${ }^{44}$, por tanto con intervención de una comisión dictaminadora, presentación de enmiendas y fase plenaria.

La modificación de la praxis de convalidación podría hacerse sin especiales problemas, presentando inmediatamente el Gobierno un proyecto de ley que se tramitaría y aprobaría dentro plazo constitucional ${ }^{45}$. Ciertamente ello dejaría sin mucho sentido a lo previsto en el ap. 3 del art. 86 sobre tramitación por el procedimiento de urgencia. Pero entendemos que esto no debería preocupar en exceso pues, como se ha reconocido por numerosos autores, esta previsión es en sí misma superflua ${ }^{46}$.

El mayor inconveniente de esta vía de reforma es la consolidada praxis actual, que hace presumir que los operadores institucionales no se prestarán fácilmente a cambiar de procedimiento.

Por lo anterior, cara a una hipotética reforma constitucional podría recomendarse bien la explicitación de esta forma legal en el art. 86.2, con la supresión consiguiente del ap. 3, bien esta misma fórmula pero ampliando a 40/45 días el plazo del Congreso, si es que se sigue pensando (erróneamente) que los 30 actuales son insuficientes. Otra alternativa sería incluir al Senado en el proceso de

44 Concretamente dispone: La procedura normale di esame e di approvazione diretta da parte della Camera è sempre adottata per $i$ disegni di legge in material costituzionale ed elettorale, e per quelli di delegazione legislativa, per quelli di conversione in legge di decreti, per quelli di autorizzazione a ratificare trattati.

45 Implicaría la reforma del art. 151 del Reglamento del Congreso de los Diputados.

46 En este sentido J. SALAS recoge las manifestaciones críticas durante los debates constituyentes, especialmente las del senador Sánchez Agesta, calificando de apartado totalmente inútil al tercero del art. 86, posición a la que se suma. Véase Los decretos-leyes en la Constitución española de 1978, ob. cit., pp. 104 y s.; J. JimÉnEZ CAMPo refiere las perplejidad que ya despertó esta regulación en los debates constituyentes en «Las Diputaciones Permanentes y el control sobre el Decreto-ley», en Revista de derecho político, núm. 15 (1982), pp. 41 y s. I. De ОтTo comenta el carácter superfluo del ap. 3. Véase Derecho constitucional sistema de fuentes, Ed. Ariel, Barcelona, 1987, p. 208. P. Santolaya implícitamente reconocía que este procedimiento habría tenido sentido tramitando el proyecto de ley dentro del plazo de un mes. Véase El régimen constitucional de los decretos-leyes, Ed. Tecnos, Madrid, 1988, pp. 200 y s. Por su parte, I. Astarloa escribe que el procedimiento del art. 86.3 habría tenido sentido de resultar alternativo al de convalidación del ap. 2. Véase artículo 86 en Comentarios a la Constitución española de 1978, dir. O. Alzaga, Cortes Generales, Editoriales de Derecho Reunidas, Madrid, 1996, t VII p. 226. 
convalidación ampliando hasta 50 o 60 días el plazo comentado (como en la fórmula italiana anterior a su reforma).

La supresión del art. 86.3, lejos de perjudicar, sería beneficiosa, pues simplificaría el inflacionista procedimiento legislativo actual, que da lugar a tres manifestaciones sobre el mismo tema en breve espacio de tiempo: el Decreto-ley originario, el acuerdo de convalidación que mantiene la fuerza y rango de ley y la ley posterior tramitada por el procedimiento de urgencia. Si la convalidación se hace por ley tras un procedimiento abierto y participativo, tal como propugnamos, no debería existir el menor reparo en prescindir de esta alternativa.

\section{Sobre el control de los hechos determinantes de los decretos-leyes}

Como vimos, tanto la Constitución italiana como la española nacieron con el noble propósito de impedir el abuso de la legislación de urgencia, que tanto merma la posición del poder legislativo.

Sin embargo, los resultados en los dos países son claramente decepcionantes ante una práctica en el que el término abuso llega a quedarse corto.

En este apartado la reforma constitucional italiana no parece aportar novedades. Por tanto, y a resultas de lo que se comenta en el apartado siguiente, no cabe hacerse muchas ilusiones sobre utilización más justificada de los decretosleyes en el futuro.

$Y$ es que las buenas intenciones de domeñar los abusos chocan con una realidad doblemente irreductible: el supuesto de hecho en sí y el llamado a controlarlo.

Por un lado, el supuesto «extraordinaria y urgente necesidad» implica un concepto esencialmente elástico y, por lo mismo, difícil de gestionar en clave jurídica. Queremos decir que ese supuesto puede ser valorado por cualquiera, pero siempre o casi siempre desde un prisma de oportunidad. Por tanto, se trata de un concepto donde prima lo subjetivo, lo maleable, lo que le hace poco apto para la objetividad que requiere el juicio jurídico ${ }^{47}$.

${ }^{47}$ El supuesto de hecho del art. 86.1 podría invitar a aplicar la técnica de los «conceptos jurídicos indeterminados», tan ampliamente estudiada por los administrativistas. Sin embargo, media una diferencia importante con dicho supuesto, como es que tales «conceptos jurídicos indeterminados» se han barajado principalmente respecto a los incluidos en las leyes, siendo así que el supuesto de hecho del art. 86.1 tiene rango constitucional y, por lo mismo, una condición más abierta. Pero es que incluso los autores más partidarios de la aplicabilidad de estos conceptos indeterminados admiten que, junto a un núcleo de certeza, controlable por los tribunales, poseen también un halo de imprecisión o de posible incertidumbre. En este sentido puede verse, E. GARCía de Enterría, Democracia, jueces y control de la Administración, Ed. Civitas, Madrid, 2009, especialmente pp. 146-154. Previamente F. SAINZ Moreno había señalado que cuando el criterio 
El Tribunal Constitucional español de facto ha reconocido esta realidad, bien que reservándose un postrer control: baste citar a la STC 48/2015, de 5 de marzo, f. 3, que, recogiendo una constante jurisprudencia, declara que «sin perjuicio del peso que en la apreciación de lo que haya de considerarse como caso de extraordinaria y urgente necesidad haya de concederse al juicio puramente político de los órganos a los que incumbe la dirección del Estado, es función propia de este Tribunal el aseguramiento de estos límites, la garantía de que en el ejercicio de esta facultad, como de cualquier otra, los poderes públicos se mueven dentro del marco trazado por la Constitución, de forma que este Tribunal podrá, en supuestos de uso abusivo o arbitrario, rechazar la definición que los órganos políticos hagan de una situación determinada como de "extraordinaria y urgente necesidad" y, en consecuencia, declarar la inconstitucionalidad de un Real Decreto-ley por inexistencia del presupuesto habilitante por invasión de las facultades reservadas a las Cortes Generales por la Constitución» (STC 137/2011, de 14 de septiembre, FJ 4)». La cursiva es nuestra.

Por otro lado, y sobre todo, no se puede ignorar que el órgano llamado a controlar su presencia no es un órgano administrativo, al que con todo sentido puede exigírsele el sometimiento pleno a la ley y el Derecho, que impone el art. 103 de la Constitución, sino un órgano cien por cien político, al que no cabe reclamar actitudes extrañas a su naturaleza ${ }^{48}$. Consiguientemente, la relación Administración-tribunales de justicia es muy distinta a la que media entre el Parlamento o poder legislativo y el Tribunal Constitucional. Lo que corresponda a este poder debe ser examinado con un canon mucho más flexible.

La propia experiencia italiana anterior a la reforma constitucional en ciernes avala lo anterior. En noviembre de 1981 y en 1997 se reformó el reglamento de la Cámara para controlar la presencia de los presupuestos de necesidad y urgencia. En concreto, según la redacción todavía vigente del art. 96-bis, el proyecto de ley de conversión se remite, además de a la comisión que deba informar de su contenido, al Comité para la legislación, que debe expresar su parecer sobre la

de una decisión administrativa es político el mismo queda fuera del examen jurídico y solo sería enjuiciable políticamente. Otra cosa serían los elementos reglados que sí resultarían controlables por los tribunales. Véase Conceptos jurídicos, interpretación y discrecionalidad administrativa, Ed. Civitas, Madrid, 1976, p. 312. En el otro extremo, autores como M. Beltrán de Felipe, rechazan por completo que los jueces puedan sustituir a la Administración en la interpretación de la discrecionalidad administrativa. Véase de este autor Discrecionalidad administrativa y constitución, Ed. Tecnos, Madrid, 1995, pp. 255 y s.

48 Tempranamente I. DE OTTO advirtió que extraordinaria y urgente necesidad es un concepto en que es forzoso reconocer a los órganos políticos un razonable margen de discrecionalidad. Véase Derecho constitucional sistema de fuentes, ob. cit., pp. 197 y s. 
especificidad y homogeneidad y los límites del decreto-ley. Se añade (ap. 2) que la memoria del Gobierno debe dar cuenta de la concurrencia de los presupuestos de necesidad y urgencia. En el Senado se sigue un trámite parecido, si bien es la comisión constitucional la que asume esa verificación.

Pues bien, este filtro o control parlamentario ha servido de muy poco, vista la utilización sistemática de la legislación de urgencia, según testimonian De Ciolo y L. Ciaurro ${ }^{49}$ y A. Mannino ${ }^{50}$ : las mayorías no han podido escapar a la dinámica partidista.

Por eso estimamos que la actitud del Tribunal Constitucional -en ocasiones tildada de tímida por no controlar con más ahínco la presencia del supuesto de hecho- resulta comprensible ${ }^{51}$. Otros aspectos de su jurisprudencia podrán ser criticados, pero este entendemos que no. Una actitud más activa del tribunal en esta función podría haber acabado en la sustitución del juicio del Congreso por el suyo propio. Y siendo este juicio, como decimos, básicamente político, a la larga se podría haber desembocado en una indiferencia de funciones, que es tanto como decir politización del órgano de garantías constitucionales.

La convalidación del decreto-ley por el Congreso implica que el órgano político por excelencia da por buena su aprobación por el Gobierno ${ }^{52}$. Y si el dueño del negocio hace esto quiere decir que asume como propia la decisión del ejecutivo. Tras la convalidación el decreto-ley debe tomarse como si lo hubiese aprobado el poder legislativo, en definitiva como si fuese una ley ${ }^{53}$. En esa circuns-

49 Véase Il diritto parlamentare nella teoría en nella pratica, Giuffré Editore, Milán, 2013, pp. 641 y s.

50 Vease Diritto parlamentare, Giuffré Editore, Milán, 2010, p. 263. En sentido parecido se manifiestan L. Gianniti y N. LuPo, Corso di diritto parlamentare, Ed. Il Mulino, 2013, p. 244.

51 También esta es otra consecuencia que puede extraerse de la experiencia italiana. Hasta 1996 el Tribunal Constitucional italiano reconoció la soberanía del Parlamento y, por tanto, la irreversibilidad de la conversión aprobada. Ante la proliferación de decretos-leyes, ya la sentencia n. 29 de 1995 declaró que la presencia del presupuesto de hecho podía ser objeto de escrutinio. Luego la sentencia 171 de 2007 llegó a anular una disposición por evidente ausencia de este presupuesto. Tal vicio no podría sanarse por la ley de convalidación. En un plano distinto la sentencia n. 360 de 1996 declaró ilegítima la reiteración de decretos-leyes. Sobre esta jurisprudencia nos remitimos al anterior apartado $\mathrm{V}$.

Sin embargo, como reconocen los autores citados en nota anterior, esta jurisprudencia no ha servido para contener el uso indiscriminado de la legislación de urgencia.

52 En este sentido C. Esposito escribió que la ley convalidación sustituye enteramente el decreto del gobierno. Véase Decreto-legge en Enciclopedia del diritto, Giuffré, Milán, tomo XI, p. 849. Con ligeros matices han defendido esta tesis autores como Santi Romano, Crisafulli y Paladin, según refiere F. VARI, La conversione del decretto-legge, Bardi editore, Roma, pp. 89-110.

53 La misma palabra «convalidación» empleada en el art. 86.2 implica este significado. Según el Diccionario de la Real Academia, convalidación significa confirmar o revalidar algo, especial- 
tancia no parece razonable que el Tribunal Constitucional pueda discutir al Congreso su decisión de declarar como propia la previa del Gobierno. Salvo, naturalmente, que se trate de una infracción profunda y evidente.

Precisamente por eso hemos insistido y ahora reiteramos la necesidad de que la convalidación se haga mediante la presentación y discusión de un proyecto de ley, con enmiendas, fase de comisión y de pleno: de esta forma se da ocasión al Parlamento para debatir cara a la opinión pública si ha habido o no extraordinaria y urgente necesidad, y si las medidas contenidas en el mismo estaban justificadas. Adicionalmente, permite enmendar el texto inicial del Gobierno.

Este control parlamentario no solo resultaría coherente con la decisión que se valora, sino que por su inmediatez supondría un mínimo freno frente al abuso gubernamental. Ciertamente, como revela la experiencia italiana, el freno no es muy potente. Pero no hay alternativa mejor.

El control por el Tribunal Constitucional siempre resultaría tardío. En semejante tesitura no se comprende que se declare inconstitucional un decreto-ley por ausencia del supuesto de hecho, pues lo mismo conllevaría una consecuencia de tanta gravedad como es su nulidad (art. 164.2 CE y 39.1 LOTC). El contenido normativo de un decreto-ley puede ser perfectamente respetuoso con la Constitución e, incluso, contener medidas que políticamente quepa calificar de oportunas o positivas. En semejante situación sería una desproporción anular todo ese conjunto de medidas simplemente porque un órgano jurisdiccional discrepa sobre la presencia de un supuesto de hecho esencialmente político. Ciertamente, una excepción se produciría a favor del control cuando la ausencia de los requisitos del art. 86.1 fuese manifiesta y grave.

Es probable que la intuición de lo anterior sea lo que ha llevado al Tribunal Constitucional a un self restraint ${ }^{54}$. Si es así, merece reconocimiento.

\footnotetext{
mente un acto jurídico, y, a su vez, confirmar en su cuarta acepción equivaldría en los contratos o actos jurídicos con vicio subsanable de nulidad, a remediar este defecto expresa o tácitamente.

${ }^{54}$ Solo en contadas ocasiones el Tribunal Constitucional ha declarado inconstitucional un decreto-ley por falta de presupuesto habilitante. Pero esto se ha producido en casos de aprobación posterior de una ley por el procedimiento del art. 86.3, de tal modo que al anular el decreto-ley la situación se mantenía inalterada gracias a la vigencia de esa ley posterior. Concretamente esto es lo que pasó con el Decreto-ley 8/2014, declarado en parte inconstitucional y nulo por la STC 199/2015, de 24 septiembre. Pero dicho decreto-ley había sido sustituido con idéntico contenido por la Ley 18/2014, de 15 de octubre, no impugnada y por lo mismo vigente.

Por su parte, la reciente STC 126/2016 declara inconstitucional y nula la concesión de un crédito extraordinario por el Real Decreto-ley 10/2014, de 1 de agosto, pero sin que de lo mismo se puedan derivar consecuencias de revisión para actuaciones administrativas firmes, para así proteger la buena fe de terceros.
} 


\section{Sobre los límites materiales y formales de los decretos-leyes}

Como vimos, el proyectado art. 77 de la Constitución italiana establece unos límites materiales a la legislación de urgencia, unas materias que están vedadas al decreto-ley. No se trata de una novedad absoluta, pues ya la Ley n. 400 de 23 de agosto de 1988 había introducido algunos de estos límites: prohibición de que el Gobierno pueda concederse así una delegación legislativa; de regular materias incluidas en el art. 72 último párrafo de la Constitución; de renovar disposiciones de un decreto-ley no convertido por una de las dos cámaras; de regular relaciones jurídicas surgidas de decretos no convertidos oportunamente, y de reintroducir disposiciones declaradas ilegítimas por el Tribunal Constitucional por vicios no procedimentales. En realidad lo que hace la reforma es elevar al máximo rango estos límites preexistentes y que el Tribunal Constitucional había estimado vinculantes para el gobierno ${ }^{55}$.

Desde luego estos límites son más reducidos que los que dispone el art. 86.1 de la Constitución española. En todo caso, hasta ahora, en cuanto límites legales, no parecen haber sido un dique frente al recurso injustificado a la legislación de urgencia. Puede haber influido que al ser la ley de conversión del mismo rango que la citada n. 400 de 23 de agosto de 1988, y al amparo del principio lex posterior derogat anterior, resultaba jurídicamente posible omitir estos límites. En esa medida cabe esperar que su elevación de rango pueda dar más juego en el futuro, esto es, que la posibilidad de viciar de inconstitucionalidad al decreto-ley atempere su utilización.

Tampoco es enteramente nueva la exigencia de contener medidas de inmediata aplicación y de carácter homogéneo (misure di inmediata applicazione e di contenuto specifico, omogeneo e corrispondente al titolo). Ya el reglamento de la Cámara de diputados contenía previsiones en este sentido ${ }^{56}$. Y el Tribunal Constitucional ha insistido, como vimos, en esta exigencia.

Esta nueva disposición, por su rango constitucional, y a pesar de su aparente modestia, puede ser de las más efectivas contra la proliferación indiscriminada

55 En este sentido puede verse A. MoRElli Notazioni sulle novitá della reforma costituzionale riguardo alla decretazione d'urgenza e al rinvio presidenziale delle leggi di conversione, federalismi.it Rivista di diritto pubblico italiano comoparato e europeo 1 junio 2016.

56 Concretamente su art. 96 bis ap. 1 prevé que la Comisión de legislación proponga la supresión de medidas contenidas en un decreto ley sujeto a conversión que sean contrarias a la especificidad y homogeneidad. Además, su ap. 7 autoriza al presidente para no admitir las enmiendas de adición extrañas a la materia regulada. En el Senado el informe de la junta del reglamento de 8 de noviembre 1984 exige un control riguroso de las enmiendas de adición que puedan ser extrañas al decreto ley de cuya conversión se trata. 
de decretos-leyes, en la medida que evitará la vertiente más aberrante de los mismos, como son los de contenido heterogéneo o ómnibus, en los que la regulación de una materia, acaso justificada, sirve de cobertura para hacerlo lo mismo con otras varias en las que no se presenta la urgencia extraordinaria.

Si bien las normas de contenido heterogéneo deben ser evitadas con carácter general, puede ocurrir que se den en la práctica. En el caso de los decretos-leyes, la extraordinaria y urgente necesidad debe apreciarse en todas sus previsiones. Recordemos cómo la sentencia n. 22 de 2012 destacó la necesidad de homogeneidad en la materia o el fin perseguido.

Esta patología también la sufrimos en España, como con razón ha denunciado M. Aragón Reyes ${ }^{57}$. Por ejemplo, el decreto-ley 20/2012, de 13 de julio, regulaba materias tan dispares como racionalización de las Administraciones públicas, seguridad social y empleo, sistema de dependencia, medidas fiscales, liberalización comercial, infraestructuras, transporte y vivienda, supresión de desajustes en el sector eléctrico, amén de otras disposiciones. A su vez, estas disposiciones afectaban a distintas leyes dentro de cada sector y contenían una regulación bastante detallada. Vista esta situación ¿puede afirmarse que todas ellas obedecían al presupuesto constitucional de extraordinaria y urgente necesidad? ${ }^{58}$

Por eso, estimamos que podría ser útil, cara a una posible reforma constitucional en España, incluir esta limitación de contener medidas de carácter homogéneo. A partir de ese momento, resultaría mucho más difícil colar reformas amparándose de algunas medidas realmente urgentes.

Lo mismo debe decirse respecto a la exigencia de que la legislación de urgencia contenga solo medidas de inmediata aplicación. Lo contrario ha sido y es una vía para escamotear la intervención del Parlamento. Un reciente ejemplo de lo anterior lo encontramos en la reciente STC 126/2016, de 7 de julio, en la que se anula un decreto-ley que concede un crédito extraordinario para atender un gasto que era perfectamente previsible.

57 Véase respecto al Decreto-ley 1/2014, de 24 de enero, de reforma en materia de infraestructuras y transporte, y otras medidas económicas M. ARAgón ReYes, Uso y abuso del Decreto-Ley. Una propuesta de reinterpretación constitucional, Real Academia de Jurisprudencia y Legislación, Madrid, 2016, pp. 127 y s.

58 Otro ejemplo lo encontramos en el Decreto-ley 29/2012, de 28 de diciembre, que mezcla cuestiones tan heterogéneas como el régimen de empleados de hogar con el del sector eléctrico y de hidrocarburos. 


\section{CONCLUSIÓN}

La experiencia italiana y la reforma del art. 77 de la Constitución demuestran que no hay soluciones fáciles en la cuestión de los decretos-leyes.

El noble y compartido deseo de evitar el recurso injustificado a los mismos se enfrenta a elementos estructurales del sistema, como son unos usos muy arraigados y el sometimiento de la mayoría parlamentaria a las decisiones del Gobierno.

Una vez creada la vía de la legislación de urgencia, es difícil evitar que el Gobierno caiga en la tentación de su utilización en casos no justificados, dadas las indudables ventajas que esta vía comporta frente al procedimiento legislativo ordinario: aprobación inmediata de todo tipo de medidas y evitación de las críticas y fiscalización que se darían en otro caso. Tampoco cabe olvidar el interés coincidente de lobbies y grupos de interés poderosos.

Teóricamente sería hasta posible suprimir la categoría de los decretos-leyes. La legislación gubernativa de urgencia se comprendía mejor en el siglo xIX y primara parte del xx, en los que el Parlamento era un órgano de difícil convocatoria o reunión inmediata. Nada de esto ocurre hoy día en que los veloces medios de transporte y las técnicas de comunicación permiten organizar reuniones en tiempos antes impensables. Desde un prisma puramente técnico es posible que el Parlamento apruebe una ley en un plazo record, aplicando por ejemplo el procedimiento de lectura única. De hecho, en países como Alemania los decretos-leyes han desaparecido a efectos prácticos: la exigente regulación del art. 81 de la Ley Fundamental para la situación de urgencia legislativa (Gesetzgebungsnotstand $\left.{ }^{59}\right)$ ha traído como consecuencia que esta vía permanezca inédita ${ }^{60}$.

El mismo hecho de que el enorme ámbito material del art. 86.1 de la Constitución haya, a pesar de su importancia, permanecido ajeno al decreto-ley demostraría que esta vía no es tan indispensable como en ocasiones se quiere hacer creer. Esto es, si todas esas materias excluidas han podido permanecer así,

59 Esencialmente supone que el Bundestag rechaza un proyecto de ley calificado como urgente por el gobierno. Entonces el Presidente federal puede, a solicitud del gobierno y con la aprobación del Bundesrat, declarar el estado de urgencia legislativa. Si el proyecto es nuevamente rechazado por el Bundestag o modificado de modo inaceptable, el Gobierno con el consentimiento del Bundesrat lo aprueba como ley.

${ }^{60}$ Así lo afirman B-O. BRYDE, en Parlamentsrecht und parlamentspraxis in der Bundesrepublik Deutschland: ein Handbuch, edits. H.-P. Schneider y W. Zeh, Walter de Gruyter, Berlin, 1989, p. 881, y D. SchnapaufF, en Grundgesetz für die Bundesrepublik Deutschland, Hömig Herausgegeber, Ed. Nomos, 2010, p. 481.

De todas formas, la experiencia alemana lleva a reconocer que es posible prescindir de los decretos-leyes en un sistema parlamentario. No obstante, ello parece condicionado por la mentalidad y las circunstancias particulares de cada país. 
no muy distinta debería ser la solución para otros sectores del ordenamiento jurídico.

Sin embargo, las modificaciones radicales no suelen ser viables, entre otras cosas porque se enfrentan a arraigados estados mentales. Por eso, parece preferible optar por reformas parciales, menos ambiciosas, reformas que permitan corregir los abusos existentes, aun a sabiendas de que no alcanzarán el grado óptimo y que aparecerán decretos-leyes de dudoso respeto al presupuesto constitucional. En este sentido, la experiencia italiana ofrece a nuestro juicio dos aportaciones que pueden ser positivas.

La primera sería la verificación de la convalidación mediante ley formal, quedando el Gobierno obligado a presentar un proyecto de ley ad hoc. Esta fórmula aseguraría un mayor debate en el Congreso, con fase de enmiendas, comisión y pleno. No es mucho, pero sí al menos brinda a la oposición la ocasión de denunciar el uso injustificado del decreto-ley y ofrecer alternativas. Por otro lado, permitiría acabar con la duplicación escasamente funcional de las leyes tramitadas por el procedimiento de urgencia (art. 86.3).

Por supuesto, la ley de convalidación tendría que ceñirse a la materia regulada por el decreto-ley, sin introducir normas extrañas a su contenido.

El modelo italiano confirma lo que siempre hemos defendido en el sentido de que es perfectamente posible aprobar leyes unicamerales, aun en países en los que el poder legislativo se comparte normalmente por las dos cámaras. Y también confirma que esa convalidación puede hacerse perfectamente en el plazo de 30 días, bien que aplicando un procedimiento de urgencia ${ }^{61}$.

También podría ser útil establecer nuevos límites materiales de los decretosleyes, como serían los recogidos en la nueva regulación italiana: obligación de ceñirse a medidas de inmediata aplicación y regulación de carácter homogéneo. Esto excluiría o al menos haría mucho más difícil los decretos-leyes que reforman sectores muy variados, donde el abuso alcanza su grado superlativo.

En el mismo sentido se insertaría la prohibición expresa de utilizar decretosleyes para aprobar presupuestos, créditos extraordinarios y suplementos de crédito. Igualmente debería incluirse entre las materias vedadas la concesión de la autorización parlamentaria para ratificar o adherirse a un convenio internacional, como pasó con el Real Decreto-ley 14/1998, de 9 de octubre, que tuvo que ser anulado por la STC 155/2005, de 9 de junio ${ }^{62}$.

${ }^{61}$ Como dijimos más arriba, podría ampliarse este plazo e incluso incluir al Senado llevando el plazo hasta cincuenta días.

62 Sobre este caso puede verse F. Santaolalla, Decreto-ley, ley y tratado internacional. Comentario a la STC 155/2005, de 9 de junio, en Teoría y realidad constitucional, UNED, núm. 18, 2006, pp. 399-428. 
Todo lo anterior puede servir, como decimos, para rebajar sensiblemente el recurso injustificado a la legislación de urgencia.

\title{
Title:
}

The reform of the decree-laws in Italy and lessons that can be obtained for the Spanish case.

\section{Summary:}

I. Introduction: the Italian constitutional reform. II. The question of the decree -laws: similarities and differences. III. The pathological application of the decree- laws. IV. The practical different situations in Italy and in Spain. V. The response of the Constitutional Court. VI. The reform of the article 77 of the Italian Constitution. VII. Lessons that can be obtained for the Spanish case. 1. Form of validation of the decree-laws. 2. Control of the determinant facts of the decree-laws. 3. Material and formal limits of the decree-laws. VIII. Conclusion.

\section{Resumen:}

Probablemente sea Italia el país donde más se ha abusado de la vía de los decretos-leyes. Esta situación también es conocida en España. Por eso la reforma constitucional italiana resulta de sumo interés, pues introduce una serie de medidas destinadas a evitar esa situación. En conjunto, la experiencia italiana ofrece a los españoles algunas disposiciones que podrían resultar positivas, como serían la presentación y tramitación de un proyecto de ley de convalidación, lo que abre paso a un control parlamentario más acentuado, la obligación de que los decretos-leyes contengan normas de inmediata aplicación y carácter homogéneo y la prohibición de utilizar esta vía para aprobar medidas presupuestarias y tratados internacionales.

\begin{abstract}
:
Probably Italy is the country where the abuse of urgency legislation (decree-laws) is paramount. This situation is also known in Spain. Therefore the recent Italian constitutional reform offers a great interest, since it introduces a series of measures aimed at preventing this
\end{abstract}


situation. Altogether, the Italian experience provides some provisions that could be positive in Spain, such as the presentation and discussion of a draft law on the validation of the decree-law, so far it paves the way to a more intensified parliamentary control, the obligation that the decree-laws contain rules of immediate application and homogeneous character and the prohibition to use this path to approve budget measures or international treaties.

Palabras clave:

Decreto-ley - convalidación - control parlamentario.

Key words:

Decree-law - urgency legislation - validation - parliamentary control. 